\title{
Distribution of $\alpha$-tocopherol stereoisomers in mink (Mustela vison) organs varies with the amount of all-rac- $\alpha$-tocopheryl acetate in the diet
}

\author{
Lone Hymøller ${ }^{1}$, Saman Lashkari ${ }^{1}$, Tove N. Clausen ${ }^{2}$ and Søren K. Jensen ${ }^{1 *}$ \\ ${ }^{1}$ Department of Animal Science, Aarhus University, Blichers Alle' 20, DK-8830 Tjele, Denmark \\ ${ }^{2}$ Copenhagen Fur Research Centre, Herningvej 112 C, DK-750O Holstebro, Denmark \\ (Submitted 24 May 2018 - Final revision received 20 August 2018 - Accepted 4 September 2018 - First published online 17 October 2018)
}

\section{Abstract}

Synthetic $\alpha$-tocopherol has eight isomeric configurations including four 2R (RSS, RRS, RSR, RRR) and four 2S (SRR, SSR, SRS, SSS). Only the RRR stereoisomer is naturally synthesised by plants. A ratio of 1.36:1 in biopotency of $R R R$ - $\alpha$-tocopheryl acetate to all-rac- $\alpha$-tocopheryl acetate is generally accepted; however, studies indicate that neither biopotency of $\alpha$-tocopherol stereoisomers nor bioavailability between them is constant, but depend on dose, time, animal species and organs. A total of forty growing young male mink were, after weaning, assigned one of the following treatments for $90 \mathrm{~d}$ : no $\alpha$-tocopherol in diet (ALFA_0), $40 \mathrm{mg} / \mathrm{kg} R R R$ - $\alpha$-tocopheryl acetate (NAT_40), $40 \mathrm{mg} / \mathrm{kg}$ all-rac$\alpha$-tocopheryl acetate (SYN_40) and $80 \mathrm{mg} / \mathrm{kg}$ feed all-rac- $\alpha$-tocopheryl acetate (SYN_80). Mink were euthanised in $\mathrm{CO}_{2}$ and blood was collected by heart puncture. Mink were pelted and liver, heart, lungs, brain and abdominal fat were collected for $\alpha$-tocopherol stereoisomer analysis. The proportion of $R R R$ - $\alpha$-tocopherol decreased in all organs and plasma with increasing amount of synthetic $\alpha$-tocopherol stereoisomers in the diet $(P \leq 0.05)$, whereas the proportion of all synthetic $\alpha$-tocopherol stereoisomers increased with increasing amount of synthetic $\alpha$-tocopherol stereoisomers in the diet $(P \leq 0.05)$. The proportion of $\alpha$-tocopherol stereoisomers in plasma, brain, heart, lungs and abdominal fat showed the following order: RRR $>R R S, R S R, R S S>\Sigma 2 S$, regardless of $\alpha$-tocopherol supplement. The liver had the highest proportion of $\Sigma 2 S$ stereoisomers, and lowest proportion of $R R R$ - $\alpha$-tocopherol. In conclusion, distribution of $\alpha$-tocopherol stereoisomers differs with dose and form of $\alpha$-tocopherol supplementation. The results did also reveal the liver's role as the major organ for accumulation of $\Sigma 2 S$ $\alpha$-tocopherol stereoisomers.

Key words: Vitamin E: Dose: $\alpha$-Tocopherol stereoisomers: Mink

An adequate and balanced supply of $\alpha$-tocopherol is important for proper growth and an effective immune response ${ }^{(1)}$. Furthermore, $\alpha$-tocopherol acts as an antioxidant in the body, as well as in the feed ${ }^{(2)}$. Mink feed is characterised by a high content of protein, a low content of carbohydrates and a high content of fat, often polyunsaturated of marine origin. The demand for antioxidants is therefore considered to be high ${ }^{(3)}$. The typical source of supplemental $\alpha$-tocopherol is synthetic manufactured racemic mixture (all-rac) but $R R R$ - $\alpha$-tocopherol is also available as a feed additive. $\alpha$-Tocopherol exists in eight different isomeric configurations including four with $2 R$ configuration (RSS, RRS, RSR, RRR) and four with $2 S$ configuration ( $S R R$, $S S R, S R S, S S S)$. The RRR isomer is the only form of $\alpha$-tocopherol occurring in nature ${ }^{(1)}$, whereas $\alpha$-tocopherol used for feed additives consists of a racemic mixture of all eight stereoisomers. In commercial vitamin mixtures, all-rac- $\alpha$-tocopherol is typically acetylated, in order to stabilise its functional phenol group during storage, and added to rations as all-rac- $\alpha$-tocopheryl acetate.
This acetylated form of $\alpha$-tocopherol must be hydrolysed before it can be absorbed from the gastro-intestinal tract ${ }^{(2)}$, but in mink hydrolysis is not the limiting factor in the absorption of $\alpha$-tocopherol as opposed to, for example, newly weaned piglets ${ }^{(4,5)}$.

The biopotency of the $R R R$ stereoisomer of $\alpha$-tocopherol is higher than the biopotency of the synthetic stereoisomers of $\alpha$-tocopherol and the ratio of $1 \cdot 36: 1$ in biopotency of $R R R$ $\alpha$-tocopheryl acetate to all-rac- $\alpha$-tocopheryl acetate is generally reported when working with $\alpha$-tocopherol supplementation ${ }^{(6)}$. However, several studies have indicated that neither the biopotency of $\alpha$-tocopherol stereoisomers nor the bioavailability between them is constant, but rather dose- and dose-time dependent and differs significantly between organs and tissues ${ }^{(7,8)}$. In rats, biodiscrimination against the different stereoisomers in plasma and tissues largely reflects the specific stereoisomer biopotency $^{(7)}$. In humans, only $2 R$ - $\alpha$-tocopherols are considered to have biological activity, and thus a ratio of $2: 1$ is used $^{(9)}$. A recent study on the concentration of stereoisomers of

Abbreviations: ALFA_0, control diet with no $\alpha$-tocopherol supplement; NAT_40, $40 \mathrm{mg} / \mathrm{kg} R R R$ - $\alpha$-tocopheryl acetate; SYN_40, diet containing $40 \mathrm{mg} / \mathrm{kg}$ all-rac$\alpha$-tocopheryl acetate; SYN_80, diet containing $80 \mathrm{mg} / \mathrm{kg}$ all-rac- $\alpha$-tocopheryl acetate.

* Corresponding author: S. K. Jensen, fax +45871502 01, email skj@anis.au.dk 
$\alpha$-tocopherol in the human infant brain showed severe discrimination against all synthetic stereoisomers of $\alpha$-tocopherol in this organ ${ }^{(10)}$. In addition, it has been reported that $R R R-\alpha$-tocopherol is the predominant stereoisomer of $\alpha$-tocopherol in human breast milk ${ }^{(11)}$. Rats accumulate a relatively high amount of $2 S$ stereoisomers $^{(7)}$ and cannot be considered as an appropriate model for humans in this respect. Mink's accumulation of stereoisomers of $\alpha$-tocopherol in plasma and tissues differs from rats, and seems to be more similar to humans ${ }^{(7)}$. The aim of this study was to determine the distribution of $\alpha$-tocopherol stereoisomers in plasma and organs from mink fed different levels and sources of $\alpha$ tocopherol.

\section{Methods}

This study complied with the Danish Ministry of Justice Law No. 474 (15 May 2014) concerning experiments with animals and care of animals used for experimental purposes and was conducted under the approval of the Danish Veterinary and Food Administration under the Danish Ministry of Environment and Food. The studies were carried out at the Copenhagen Fur Research Centre in Holstebro, Denmark, between July and November 2015.

\section{Animals, housing and feeding}

In the present study, forty brown male mink were used. All mink were traditionally housed in wire netting cages in pairs of one male and one female throughout the study. All animal facilities were sheltered under permanent outdoor sheds. Basic rations were wet mink feed rations composed of industrial fish (30\%), poultry (15\%), grain (barley/wheat) (15\%), fish silage $(6 \%)$, soya oil (6\%), fish offal $(5 \%)$, potato protein/maize gluten $(5 \%)$, lard $(3 \%)$, Hb meal $(2 \%)$, minerals and synthetic methionine (1\%) and water (12\%). The protein:fat:carbohydrate ratio was 30:55:15 on energy basis. Basic diets were mixed before the studies, $\alpha$-tocopherol was added according to the treatment plans and subsequently stored at $-18^{\circ} \mathrm{C}$ in 5 -kg plastic bags. The necessary number of bags of feed were thawed daily and fed to the respective treatment groups. The mink were fed once a day and had ad libitum access to water. $\alpha$-tocopherol as either all-rac- $\alpha$-tocopheryl acetate or $R R R$ - $\alpha$-tocopheryl acetate was kindly provided by Provia A/S.

\section{Treatments and study design}

The study was carried out as a dose-response study with daily supplementation with different doses of all-rac- $\alpha$-tocopheryl acetate or $R R R$ - $\alpha$-tocopheryl acetate in the feed. The mink were born in the first week of May, weaned on 1 July 2015 and male and female mink were paired and placed in cages to habituate them to the cage mate and the housing facilities. On 15 July 2015, the mink were randomly assigned to four treatment groups: no added $\alpha$-tocopherol in the feed (ALFA_0), $40 \mathrm{mg} / \mathrm{kg}$ feed $R R R$ - $\alpha$-tocopheryl acetate (NAT_ 40$), 40 \mathrm{mg} / \mathrm{kg}$ feed allrac- $\alpha$-tocopheryl acetate (SYN_40) and $80 \mathrm{mg} / \mathrm{kg}$ feed all-rac$\alpha$-tocopheryl acetate (SYN_80). Analysed contents of total $\alpha$ tocopherol and distribution of stereoisomers of $\alpha$-tocopherol in the diets by mid-November are shown in Table 1.

\section{Sample material}

In mid-November 2015, the mink were fasted for $12 \mathrm{~h}$ and subsequently euthanised in $\mathrm{CO}_{2}$. A blood sample was taken by heart puncture, the mink were pelted and liver, heart, lungs, brain and a sample of abdominal fat collected. All sample material was stored at $-18^{\circ} \mathrm{C}$ until analysis.

\section{Chemical analyses}

Chemical analyses for contents of $\alpha$-tocopherol and stereoisomers of $\alpha$-tocopherol were performed at the Department of Animal Science, Aarhus University. All samples and standard vitamin solutions were protected from light during preparation. $\alpha$-Tocopherol contents of plasma, organ and diet were determined as described by Jensen et al. ${ }^{(7)}$. Organ samples were homogenised by Ultra Turrax (IKA Labortechnik) in an ice bath and, like plasma and diet samples, precipitated in ethanol and methanol, saponified with potassium hydroxide and extracted in heptane. Separation and quantification of $\alpha$-tocopherol was carried out by HPLC as described by Jensen et al. ${ }^{(7)}$. The stereochemical composition of $\alpha$-tocopherol in plasma, organs and diet samples was determined after methylation of stereoisomers into their methyl esters and subsequent separation by chiral HPLC, as described by Jensen et al. ${ }^{(7)}$. Results are reported as the ratio of the observed stereoisomer among five peaks and the concentration determined by calculation of each stereoisomer concentration from total $\alpha$-tocopherol. Recovery of total $\alpha$-tocopherol was $96 \%$ with a CV (\%) of $2 \cdot 7$, whereas recovery of the individual stereoisomers varied from $95 \cdot 3$ to $100 \cdot 8 \%$ with

Table 1. Analysed content of $a$-tocopherol $(n 2)$ and distribution of stereoisomers of $a$-tocopherol in diets

\begin{tabular}{|c|c|c|c|c|c|c|c|}
\hline \multirow[b]{2}{*}{ Treatment } & \multirow[b]{2}{*}{ Total- $\alpha$-tocopherol } & \multirow[b]{2}{*}{ SEM } & \multicolumn{5}{|c|}{ Percentage of $a$-tocopherol stereoisomers } \\
\hline & & & $R R R$ & $R R S$ & $R S R$ & RSS & $\Sigma 2 S$ \\
\hline \multicolumn{8}{|l|}{$\operatorname{Diet}(\mu \mathrm{g} / \mathrm{g})$} \\
\hline NAT_40 & $37 \cdot 7$ & 0.4 & 88.4 & $2 \cdot 3$ & 1.1 & 0.8 & 7.4 \\
\hline ALFĀ_0 & 9.1 & 0.02 & $69 \cdot 0$ & 13.9 & 1.4 & 2.6 & $13 \cdot 1$ \\
\hline SYN_40 & $42 \cdot 9$ & $1 \cdot 1$ & $19 \cdot 8$ & 14.8 & $10 \cdot 7$ & 11.3 & 43.4 \\
\hline SYN_80 & $74 \cdot 4$ & 0.2 & 14.9 & $13 \cdot 1$ & 11.4 & $12 \cdot 2$ & 48.4 \\
\hline
\end{tabular}

NAT_40, $40 \mathrm{mg} / \mathrm{kg} R R R$ - $\alpha$-tocopheryl acetate; ALFA_0, control diet with no $a$-tocopherol; SYN_40, diet containing $40 \mathrm{mg} / \mathrm{kg}$ all-rac- $\alpha$-tocopheryl acetate; SYN_80, diet containing $80 \mathrm{mg} / \mathrm{kg}$ all-rac-a-tocopheryl acetate. 
CV (\%) varying from 1.2 to $7 \cdot 9$. Data were expressed per wet weight of tissue.

\section{Statistical analyses}

The statistical power was analysed in $\mathrm{SAS}^{\circledR}$ by Proc Power. The statistical power was $>0.999$ for all comparisons. Thus, the high statistical power in the present study avoided a type II error (not detecting the true difference) and ensured sufficient reliability for significant statistical differences. Differences between treatments within organ and between stereoismers in the same diets were analysed in SAS ${ }^{\circledR}$ MIXED models (SAS Institute Inc.) using the following model: $Y_{i j}=\mu+\alpha_{i}+e_{i j}$, where $Y_{i j}$ was the dependent variable (total $\alpha$-tocopherol content and stereoisomer percentage), $\alpha_{i}$ the effect of treatment $i$ and $e_{i j}$ the random residual error. Differences in total $\alpha$-tocopherol content were analysed using the model $Y_{i j}=\mu+\beta_{i}+e_{i j}$, where $Y_{i j}$ was the dependent variable (total $\alpha$-tocopherol, stereoisomer percentage), $\beta_{i}$ the effect of organs $i$ and $e_{i j}$ the random residual error. Random effects were assumed normally distributed with mean value 0 and constant variance $e \sim N\left(0, \sigma^{2}\right)$. Results are presented as least squares means and differences considered statistically significant if $P \leq 0 \cdot 05$.

\section{Results}

The diets fed to different treatment groups were analysed to confirm the content of $\alpha$-tocopherol and distribution of $\alpha$-tocopherol stereoisomers in the diets. Results of $\alpha$-tocopherol and stereoisomer distribution in different treatment groups are shown in Table 1 and are in agreement with the planned contents of $\alpha$ tocopherol in the supplemented treatment groups.

The highest and lowest contents of total $\alpha$-tocopherol in plasma, organs and abdominal fat were found in SYN_80 and ALFA_0, respectively $(P \leq 0 \cdot 05)$. No significant differences were found in total $\alpha$-tocopherol contents between SYN_40 and NAT_40 in plasma, organs or abdominal fat (Table 2). As expected, the highest proportion of $R R R$ - $\alpha$-tocopherol was

Table 2. Total $a$-tocopherol content and distribution of $a$-tocopherol stereoisomers in plasma, organs and abdominal fat $(n 10)$

\begin{tabular}{|c|c|c|c|c|c|c|c|}
\hline \multirow[b]{2}{*}{ Treatment } & \multirow[b]{2}{*}{ Total $a$-tocopherol } & \multicolumn{6}{|c|}{ Percentage of $a$-tocopherol stereoisomers } \\
\hline & & $R R R$ & $R R S$ & $R S R$ & RSS & $\Sigma 2 S$ & SEM \\
\hline \multicolumn{8}{|c|}{ Plasma $(\mu \mathrm{g} / \mathrm{ml})$} \\
\hline NAT_40 & $10 \cdot 1^{a, b}$ & $93.5^{\mathrm{W}, \mathrm{d}}$ & $3 \cdot 7^{\mathrm{X}, \mathrm{d}}$ & $0.7^{\mathrm{Y}, \mathrm{c}}$ & $1 \cdot 1^{\mathrm{Y}, \mathrm{d}}$ & $0.7^{\mathrm{Y}, \mathrm{b}}$ & $2 \cdot 8$ \\
\hline ALFA_0 & $4 \cdot 0^{\mathrm{C}}$ & $97 \cdot 4^{\mathrm{W}, \mathrm{c}}$ & $1 \cdot 8^{\mathrm{X}, \mathrm{c}}$ & $0.3^{Y, b}$ & $0.1^{\mathrm{Y}, \mathrm{c}}$ & $0.8^{Y, b}$ & $5 \cdot 2$ \\
\hline SYN_40 & $9 \cdot 2^{b}$ & $58.8^{\mathrm{W}, \mathrm{b}}$ & $15 \cdot 2^{\mathrm{X}, \mathrm{b}}$ & $10 \cdot 1^{Y, a}$ & $9 \cdot 9^{\mathrm{Y}, \mathrm{a}}$ & $5 \cdot 7^{Z, a}$ & 5.5 \\
\hline SYN_80 & $12 \cdot 2^{\mathrm{a}}$ & $56 \cdot 7^{\mathrm{W}, \mathrm{a}}$ & $16 \cdot 0^{\mathrm{x}, \mathrm{a}}$ & $11 \cdot 2^{\mathrm{Y}, \mathrm{a}}$ & $11 \cdot 2^{Y, a}$ & $4 \cdot 6^{\mathrm{Z}, \mathrm{a}}$ & $2 \cdot 6$ \\
\hline SEM & 1.27 & 5.42 & 1.77 & 1.57 & 1.63 & 0.78 & - \\
\hline \multicolumn{8}{|l|}{ Liver $(\mu \mathrm{g} / \mathrm{g})$} \\
\hline NAT_40 & $15 \cdot 1^{\mathrm{b}, \mathrm{c}}$ & $63.7^{\mathrm{W}, \mathrm{c}}$ & $6 \cdot 9^{\mathrm{Y}, \mathrm{a}}$ & $1.5^{\mathrm{Y}, \mathrm{c}}$ & $1 \cdot 8^{\mathrm{Y}, \mathrm{b}}$ & $26 \cdot 0^{\mathrm{X}, \mathrm{b}}$ & 3.7 \\
\hline ALFĀ_0 & $6 \cdot 6^{\mathrm{c}}$ & $48 \cdot 2^{\mathrm{W}, \mathrm{b}}$ & $17 \cdot 6^{Y, c}$ & $1 \cdot 7^{Z, c}$ & $2 \cdot 4^{Z, b}$ & $30 \cdot 1^{\mathrm{X}, \mathrm{b}}$ & 3.5 \\
\hline SYN_40 & $25 \cdot 5^{\mathrm{b}}$ & $25 \cdot 8^{X, a}$ & $10 \cdot 9^{Y, b}$ & $6 \cdot 2^{Y, b}$ & $6 \cdot 5^{\mathrm{Y}, \mathrm{a}}$ & $50 \cdot 6^{\mathrm{W}, \mathrm{a}}$ & 2.6 \\
\hline SYN_80 & $40 \cdot 9^{a}$ & $18 \cdot 7^{\mathrm{X}, \mathrm{a}}$ & $9 \cdot 9^{\mathrm{Y}, \mathrm{a}, \mathrm{b}}$ & $7 \cdot 8^{\mathrm{Y}, \mathrm{a}}$ & $8 \cdot 0^{Y, a}$ & $55 \cdot 6^{\mathrm{W}, \mathrm{a}}$ & 1.5 \\
\hline SEM & $6 \cdot 7$ & $6 \cdot 1$ & $2 \cdot 1$ & 0.9 & 0.9 & 5.5 & - \\
\hline \multicolumn{8}{|l|}{ Brain $(\mu \mathrm{g} / \mathrm{g})$} \\
\hline NAT_40 & $21 \cdot 7^{\mathrm{b}}$ & $86.8^{\mathrm{W}, \mathrm{c}}$ & $7 \cdot 5^{\mathrm{X}, \mathrm{c}}$ & $2 \cdot 5^{\mathrm{Y}, \mathrm{c}}$ & $2 \cdot 3^{\mathrm{Y}, \mathrm{c}}$ & $0 \cdot 7^{\mathrm{Z,b}}$ & $2 \cdot 8$ \\
\hline ALFA_0 & $13 \cdot 0^{c}$ & $76.7^{\mathrm{W}, \mathrm{b}}$ & $13 \cdot 7^{\mathrm{X}, \mathrm{b}}$ & $4.5^{\mathrm{Y}, \mathrm{b}}$ & $4 \cdot 2^{\mathrm{Y}, \mathrm{b}}$ & $0.9^{\mathrm{Z}, \mathrm{b}}$ & $4 \cdot 7$ \\
\hline SYN_40 & $19 \cdot 9^{b}$ & $58 \cdot 3^{\mathrm{W}, \mathrm{a}}$ & $18 \cdot 2^{\mathrm{X}, \mathrm{a}}$ & $9 \cdot 9^{Y, a}$ & $9.9^{Y, a}$ & $3 \cdot 7^{Z, a}$ & $4 \cdot 1$ \\
\hline SYN_80 & $27 \cdot 3^{a}$ & $59 \cdot 2^{\mathrm{W}, \mathrm{a}}$ & $16 \cdot 7^{\mathrm{X}, \mathrm{a}}$ & $10 \cdot 5^{\mathrm{Y}, \mathrm{a}}$ & $9 \cdot 8^{\mathrm{Y}, \mathrm{a}}$ & $3 \cdot 8^{z, a}$ & $2 \cdot 8$ \\
\hline SEM & 1.9 & 3.9 & 1.3 & $1 \cdot 3$ & 1.1 & 0.5 & - \\
\hline \multicolumn{8}{|l|}{ Heart $(\mu \mathrm{g} / \mathrm{g})$} \\
\hline NAT_40 & $18 \cdot 5^{\mathrm{b}}$ & $88.8^{\mathrm{W}, \mathrm{d}}$ & $5 \cdot 8^{X, d}$ & $1.6^{\mathrm{Y}, \mathrm{c}}$ & $2 \cdot 0^{\mathrm{Y}, \mathrm{d}}$ & $1 \cdot 8^{\mathrm{Y}, \mathrm{b}}$ & $2 \cdot 3$ \\
\hline ALFA__0 & $7 \cdot 8^{\mathrm{c}}$ & $77 \cdot 3^{\mathrm{W}, \mathrm{c}}$ & $14 \cdot 6^{Z, c}$ & $2 \cdot 4^{\mathrm{Y}, \mathrm{c}}$ & $3 \cdot 4^{Z, c}$ & $2 \cdot 2^{z, b}$ & 4.9 \\
\hline SYN_40 & $16 \cdot 3^{\mathrm{b}}$ & $51 \cdot 2^{\mathrm{W}, \mathrm{b}}$ & $18 \cdot 4^{\mathrm{X}, \mathrm{b}}$ & $11 \cdot 7^{\Upsilon, \mathrm{b}}$ & $10 \cdot 7^{Y, \mathrm{~b}}$ & $7 \cdot 6^{\mathrm{Z}, \mathrm{a}}$ & $4 \cdot 1$ \\
\hline SYN_80 & $22 \cdot 3^{a}$ & $44.1^{\mathrm{W}, \mathrm{a}}$ & $19 \cdot 8^{\mathrm{X}, \mathrm{a}}$ & $14 \cdot 0^{Y, a}$ & $13 \cdot 6^{Y, a}$ & $8 \cdot 4^{z, a}$ & $1 \cdot 8$ \\
\hline SEM & $2 \cdot 1$ & $5 \cdot 4$ & 1.5 & 1.7 & 1.5 & 1.1 & - \\
\hline \multicolumn{8}{|c|}{ Lungs $(\mu \mathrm{g} / \mathrm{g})$} \\
\hline NAT_40 & $6 \cdot 6^{\mathrm{b}}$ & $87.3^{\mathrm{W}, \mathrm{d}}$ & $6 \cdot 8^{\mathrm{X}, \mathrm{c}}$ & $1.6^{\mathrm{Y}, \mathrm{c}}$ & $2 \cdot 0^{\mathrm{Y}, \mathrm{d}}$ & $2 \cdot 3^{Y, b}$ & $2 \cdot 3$ \\
\hline ALFĀ_0 & $1 \cdot 8^{\mathrm{C}}$ & $74.8^{\mathrm{W}, \mathrm{c}}$ & $17 \cdot 4^{\mathrm{X}, \mathrm{b}}$ & $2 \cdot 3^{\mathrm{Y}, \mathrm{c}}$ & $2 \cdot 9^{\mathrm{Y}, \mathrm{C}}$ & $2 \cdot 8^{Y, b}$ & $4 \cdot 8$ \\
\hline SYN_40 & $5 \cdot 1^{b}$ & $51.1^{\mathrm{W}, \mathrm{b}}$ & $19 \cdot 8^{\mathrm{X}, \mathrm{a}}$ & $10 \cdot 0^{Y, b}$ & $10 \cdot 7^{Y, b}$ & $8 \cdot 5^{\mathrm{Y}, \mathrm{a}}$ & $4 \cdot 0$ \\
\hline SYN_80 & $9 \cdot 6^{a}$ & $43.5^{\mathrm{W}, \mathrm{a}}$ & $19 \cdot 6^{\mathrm{X}, \mathrm{a}}$ & $13.5^{\mathrm{Y}, \mathrm{a}}$ & $13 \cdot 8^{Y, a}$ & $9 \cdot 7^{Z, a}$ & 1.75 \\
\hline SEM & $1 \cdot 1$ & $5 \cdot 5$ & 1.8 & 1.6 & 1.5 & $1 \cdot 2$ & - \\
\hline \multicolumn{8}{|c|}{ Abdominal fat $(\mu \mathrm{g} / \mathrm{g})$} \\
\hline NAT_40 & $22 \cdot 4^{\mathrm{b}, \mathrm{c}}$ & $87.5^{\mathrm{W}, \mathrm{d}}$ & $8 \cdot 2^{\mathrm{X}, \mathrm{c}}$ & $1 \cdot 3^{\mathrm{Y}, \mathrm{d}}$ & $1 \cdot 8^{\mathrm{Y}, \mathrm{d}}$ & $1 \cdot 3^{\mathrm{Y,b}}$ & $2 \cdot 1$ \\
\hline ALFA_0 & $13 \cdot 3^{c}$ & $74 \cdot 2^{\mathrm{W}, \mathrm{c}}$ & $19 \cdot 3^{\mathrm{X}, \mathrm{a}, \mathrm{b}}$ & $1.9^{\mathrm{Y}, \mathrm{c}}$ & $2 \cdot 8^{Y, c}$ & $1 \cdot 8^{Y, b}$ & $4 \cdot 8$ \\
\hline SYN_40 & $30 \cdot 5^{\mathrm{b}}$ & $49 \cdot 5^{\mathrm{W}, \mathrm{b}}$ & $20 \cdot 2^{\mathrm{X}, \mathrm{b}}$ & $10 \cdot 5^{Y, b}$ & $11.9^{Y, b}$ & $8 \cdot 0^{\mathrm{Y}, \mathrm{a}}$ & 3.9 \\
\hline SYN_80 & $46 \cdot 1^{a}$ & $46 \cdot 5^{\mathrm{W}, \mathrm{a}}$ & $18 \cdot 5^{\mathrm{x}, \mathrm{a}}$ & $13 \cdot 1^{Y, a}$ & $13 \cdot 9^{Y, a}$ & $7 \cdot 3^{z, a}$ & 1.9 \\
\hline SEM & 5.4 & $5 \cdot 0$ & 1.6 & 1.6 & 1.6 & 3.4 & - \\
\hline
\end{tabular}

NAT_40, $40 \mathrm{mg} / \mathrm{kg}$ RRR- $\alpha$-tocopheryl acetate; ALFA_0, control diet with no $a$-tocopherol supplement; SYN_40, diet containing $40 \mathrm{mg} / \mathrm{kg}$ all-rac-a-tocopheryl acetate; SYN_80, diet containing $80 \mathrm{mg} / \mathrm{kg}$ all-rac-a-tocopheryl acetate.

${ }_{a, b, c, d}$ Mean values within a column with unlike superscript letters were significantly different $(P \leq 0.05)$.

$\mathrm{W}, \mathrm{X}, \mathrm{Y}, \mathrm{Z}$ Mean values within a row with unlike superscript letters were significantly different $(P \leq 0.05)$. 
found in NAT_40 in all organs, abdominal fat and plasma ( $P \leq 0.05)$. The proportion of $R R R$ - $\alpha$-tocopherol in ALFA_0 was lower than the NAT_40 in all organs, abdominal fat and plasma $(P \leq 0.05)$; however, the proportion of $R R R$ - $\alpha$-tocopherol in ALFA_0 was higher than in SYN_80 and SYN_40 $(P \leq 0.05)$. In liver and brain no significant differences were found in $R R R$ $\alpha$-tocopherol proportion between SYN_80 and SYN_40, whereas SYN_40 had higher RRR- $\alpha$-tocopherol proportion than SYN_80 in plasma, heart, lungs and abdominal fat $(P \leq 0.05$, Table 2). In addition, the proportion of the synthetic $2 R$ stereoisomers and the $\Sigma 2 S$ stereoisomers was higher in plasma, organs and abdominal fat in SYN_80 and SYN_40 compared with ALFA_0 and NAT_40 $(P \leq 0 \cdot 05)$. The liver was the organ that contained the highest proportion of $\Sigma 2 S$ - $\alpha$-tocopherol stereoisomers $(P \leq 0 \cdot 05$, Table 2$)$.

Comparison of $\alpha$-tocopherol stereoisomers proportion within the plasma, organs and abdominal fat within the same diets is summarised in Table 2 . The proportion of $\alpha$-tocopherol stereoisomers in plasma, brain, heart, lungs and abdominal fat showed the following order: RRR $>R R S, R S R, R S S>\Sigma 2 S$, regardless of $\alpha$-tocopherol supplement. However, a different pattern was observed in the liver in SYN_40 and SYN_80; here, $\Sigma 2 S$ - $\alpha$-tocopherol accounted for the highest proportion of $\alpha$-tocopherol stereoisomers, intermediate values for $R R R$ - $\alpha$ tocopherol and lowest for the synthetic $2 R$ - $\alpha$-tocopherols. In addition, in ALFA_0 and NAT_40, the proportion of $\alpha$-tocopherol stereoisomers in liver showed the following order: $R R R>\Sigma 2 S>R R S, R S R, R S S$.

The $\alpha$-tocopherol content and distribution of stereoisomers between plasma, organs and abdominal fat within diets containing different $\alpha$-tocopherol amount is shown in Fig. 1. In the ALFA_0 and NAT_40, the highest amount of total $\alpha$-tocopherol was observed in brain and abdominal fat; however, in diets containing the SYN_80 and SYN_40, the highest amount of $\alpha$-tocopherol was observed in liver and abdominal fat $(P \leq 0 \cdot 05)$. Regardless of $\alpha$-tocopherol supplement, lungs showed the lowest amount of total $\alpha$-tocopherol $(P \leq 0 \cdot 05)$.

\section{Discussion}

The high proportion of $R R S$ - $\alpha$-tocopherol and $\Sigma 2 S$ - $\alpha$-tocopherol in the ALFA_0 diet most likely reflects the presence of these stereoisomers in the poultry and industrial fish used and thus originate from the all-rac- $\alpha$-tocopheryl acetate fed to these animals. The present study showed a severe discrimination against systemic circulation and take up of synthetic stereoisomers of $\alpha$-tocopherol into organs. Irrespective of $\alpha$-tocopherol supplement, the $R R R$ - $\alpha$-tocopherol was the dominant stereoisomer in the plasma, organs and abdominal fat. The results revealed that non- $R R R$ - $\alpha$-tocopherol remained in the liver, compared with $R R R$ - $\alpha$-tocopherol, which was preferentially released from the liver to the plasma (Table 2). The high proportion of non-RRR- $\alpha$ tocopherol in the liver indicated the role of liver in elimination of non- $R R R$ - $\alpha$-tocopherol. These results agreed with Kaneko et $a l .{ }^{(12)}$, who found the important role of liver in degradation of radiolabelled $S R R$ - $\alpha$-tocopherol. Kaneko et $a l^{(12)}$ studied the metabolism of $\alpha$-tocopherol stereoisomers in rat and reported that radioactivity derived from $S R R$ - $\alpha$-tocopherol reached its maximum level $24 \mathrm{~h}$ after the dosage, and that derived from $R R R$ $\alpha$-tocopherol reached maximum at $48 \mathrm{~h}$; therefore, they concluded that $S R R-\alpha$-tocopherol eliminated rapidly from the liver. An early study by Ingold et $a l .{ }^{(13)}$ showed a similar preferential uptake of $R R R$ - $\alpha$-tocopheryl acetate over $S R R$ - $\alpha$-tocopheryl acetate in male Sprague-Dawley rats. Similarly, Jensen et al. ${ }^{(7)}$ showed discrimination against all synthetic stereoisomers of $\alpha$ tocopheryl acetate in male Wistar rats, with the most severe discrimination found to be against $\Sigma 2 S$-stereoisomers of $\alpha$-tocopherol. In the study by Ingold et $a l^{(13)}$, the strongest discrimination of all organs against the $S R R$ - $\alpha$-tocopherol stereoisomer was found in rat brain in agreement with the findings of the present study. In rats, the discrimination against the $S R R-\alpha$-tocopherol stereoisomer was shown by Ingold et al. ${ }^{(13)}$ to be initiated already in the gut, probably owing to incomplete hydrolysis of the acetate group of $\alpha$-tocopheryl acetate ${ }^{(4)}$, a step that, in previous studies, has been shown not to be limiting in $\operatorname{mink}^{(4,5)}$.

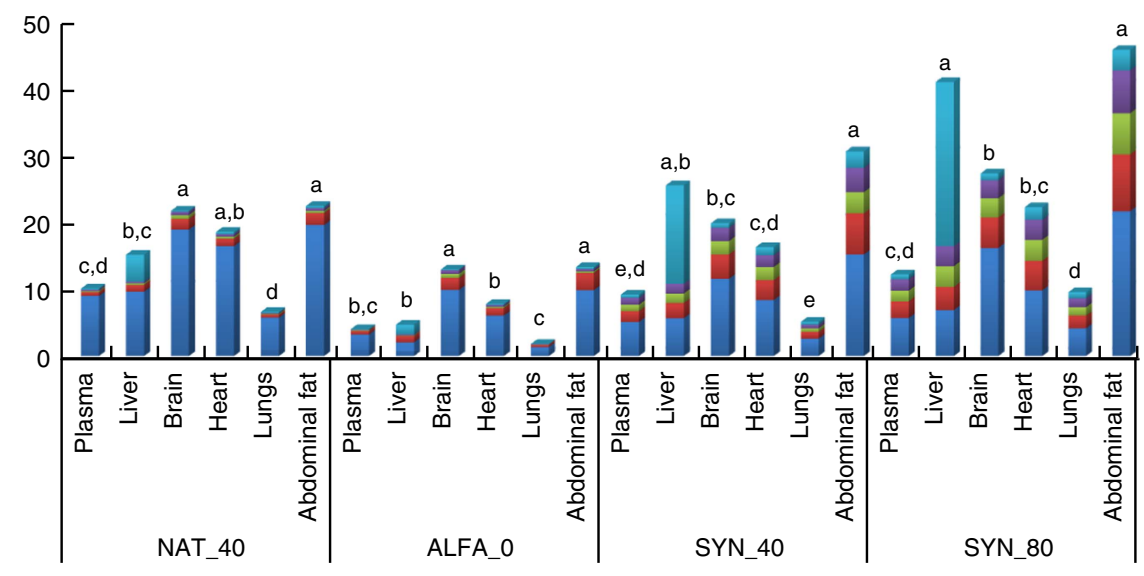

Fig. 1. Total-a-tocopherol content and stereoisomer distribution of plasma $(\mu \mathrm{g} / \mathrm{ml})$, different organs $(\mu \mathrm{g} / \mathrm{g})$ and abdominal fat $(\mu \mathrm{g} / \mathrm{g})$ within the same diets. ${ }^{\mathrm{a}, \mathrm{b}, \mathrm{c}, \mathrm{d}, \mathrm{e}} \mathrm{Mean}$ values within the same diets with unlike letters were significantly different $(P \leq 0.05)$. NAT_40, $40 \mathrm{mg} / \mathrm{kg} R R R$ - $a$-tocopheryl acetate; ALFA_0, control diet with no $a$-tocopherol supplement; SYN_40, diet containing $40 \mathrm{mg} / \mathrm{kg}$ all-rac-a-tocopheryl acetate; SYN_80, diet containing $80 \mathrm{mg} / \mathrm{kg}$ all-rac-a-tocopheryl acetate. $\square, \Sigma 2 S$; $\square, R S S ; \square, R S R ; \square, R R S ; \square, R R R$. 
The liver is considered to be the main site of the preferential biodiscrimination in favour of $\alpha$-tocopherol with $2 R$ configuration, owing to the abundant presence of $\alpha$-tocopherol transfer protein $\left(\alpha\right.$-TTP) in this tissue ${ }^{(14)}$. Consequently, the liver builds up high concentrations of synthetic stereoisomers, especially those with $2 S$ configuration. The key role of liver in elimination of $\Sigma 2 S$ - $\alpha$-tocopherol has been proven already ${ }^{(8)}$, but the high proportion of $\Sigma 2 S$ stereoisomers in livers from NAT_40 and ALFA_40 indicates higher accumulation of at least a part of the $\Sigma 2 S$ stereoisomers in the liver. The high proportion of non- $R R R$ $\alpha$-tocopherol in plasma and organs other than liver might reflect that $\alpha$-TTP accepts other $2 R$ - $\alpha$-tocopherol stereoisomers than $R R R$ - $\alpha$-tocopherol. In addition, it is likely that organs and abdominal fat uptake of $2 R$ and $\Sigma 2 S$ - $\alpha$-tocopherol stereoisomers follow the mechanisms of lipid uptake. In agreement with our finding, Hosomi et al. ${ }^{(14)}$ demonstrated the tissue uptake of $\alpha$-tocopherol by a variety of non-specific mechanisms linked to clearance of chylomicrons by lipoprotein lipase during the first pass before hepatic uptake.

Although the amount of total $\alpha$-tocopherol in brain increased from 19.9 to $27 \cdot 3 \mu \mathrm{g} / \mathrm{g}$ in SYN_40 and SYN_80, respectively, the $R R R$ - $\alpha$-tocopherol proportion did not decrease. This severe discrimination against synthetic stereoisomers of $\alpha$-tocopherol in the brain of mink found in the present study is in agreement with a recent study on the distribution of $\alpha$-tocopherol stereoisomers in the human infant brain by Kuchan et al. ${ }^{(10)}$. In their study, Kuchan et al. ${ }^{(10)}$ showed an almost complete absence of the seven synthetic stereoisomers of $\alpha$-tocopherol in the brain of infants $(0 \cdot 2-1.5 \mu \mathrm{g} / \mathrm{g}$ brain tissue) in contrast to the $R R R$ stereoisomer $(7-15 \mu \mathrm{g} / \mathrm{g}$ brain tissue). However, in that study the intake of $\alpha$-tocopherol or the stereoisomeric composition was not known. This supposedly indicates that the $R R R$ stereoisomer of $\alpha$-tocopherol is essential for the development of the brain, because biological discrimination and biological importance are usually intimately linked in the body ${ }^{(10)}$.

Generally, the difference between the $R R R$ - $\alpha$-tocopherol and the non-RRR- $\alpha$-tocopherol group (Table 2 ) supported that non$R R R$ - $\alpha$-tocopherol has poor retention in the different organs compared with $R R R-\alpha$-tocopherol. In agreement with our findings, Kaneko et $a l .{ }^{(12)}$ reported that urinary and faecal excretion of radioactivity derived from $S R R$ - $\alpha$-tocopherol was significantly greater than that derived from $R R R$ - $\alpha$-tocopherol. On the basis of Table 1 , the diets containing SYN_80 and SYN_40 had high amounts of non-RRR- $\alpha$-tocopherol; however, lower proportions of non- $R R R-\alpha$-tocopherol were observed in the plasma, organs and abdominal fat, indicating a preferential exclusion of these stereoisomers. It has been shown that all-rac- $\alpha$-tocopherol are metabolised to 2,5,7,8-tetramethyl-2-(2'-carboxyethyl)-6-hydroxychroman faster than $R R R-\alpha$-tocopherol ${ }^{(15)}$. Traber et al. ${ }^{(15)}$ also reported the higher excretion rate of all-rac- $\alpha$-tocopherol than of $R R R$ - $\alpha$-tocopherol.

In the present study, the proportion of the $R R R$ stereoisomer of $\alpha$-tocopherol in plasma and tissues decreased as expected when mink were fed diets containing all-rac- $\alpha$-tocopheryl actetate compared with NAT_40 and ALFA_0, and also when all-rac- $\alpha$-tocopheryl actetate increased from 40 to $80 \mathrm{mg} / \mathrm{kg}$ feed. The exception was the brain, where the proportion of $R R R$ - $\alpha$-tocopherol was constant between mink on SYN_40 and
SYN_80 diets. This implies that the proportion of natural and synthetic stereoisomers of $\alpha$-tocopherol is not constant, but dependent on the dose of $\alpha$-tocopherol, vitamin E source (SYN $v$. NAT) and the target $\operatorname{organ}^{(8)}$. RRS- $\alpha$-tocopherol is the synthetic $2 R$ stereoisomer with a stereochemical configuration most similar to $R R R$ - $\alpha$-tocopherol and the synthetic stereoisomer occurring with the highest proportion after $R R R$ - $\alpha$-tocopherol. This reveals the importance of the stereochemical configuration as a determinant for the distribution of $\alpha$-tocopherol stereoisomers for biopotency. Thus, Weiser \& Vecchi ${ }^{(16)}$ showed in the classical rat resorption gestation test that $R R S$ - $\alpha$-tocopherol was the $\alpha$-tocopherol stereoisomer with the highest biopotency after $R R R$ $\alpha$-tocopherol. The present study shows that discrimination of $\alpha$ tocopherol stereoisomers is complex and varies between organs within species.

\section{Conclusions}

The distribution of $\alpha$-tocopherol stereoisomers is dependent on dose and source of $\alpha$-tocopherol. Increasing the amount of synthetic $\alpha$-tocopherol stereoisomers in the diet decreased the proportion of $R R R$ - $\alpha$-tocopherol in all organs, abdominal fat and plasma, whereas the proportion of synthetic $2 R$ - $\alpha$-tocopherol increased in plasma and organs, with $R R S-\alpha$-tocopherol occurring with the highest proportion. However, the proportion of $\Sigma 2 S$ - $\alpha$-tocopherol was unaffected by SYN_40 and SYN_80 and remained low in plasma and all organs with the exception of liver. Similarly, the brains proportion of $R R R-\alpha$-tocopherol was unaffected whether the mink were fed diet SYN_40 or SYN_80. The results demonstrated that different organs discriminate stereoisomers of $\alpha$-tocopherol to a different extent.

\section{Acknowledgements}

Laboratory technician E. L. Pedersen is acknowledged for carrying out the chemical analysis and collecting organs and blood for analysis.

The study was supported by the foundation for research in furbearing animals under Copenhagen Fur, Denmark. The funder had no role in the design, analysis or writing of this article.

L. H. contributed to laboratory analyses, data analysis, interpretation of the findings and writing the final manuscript. S. L. was involved in interpretation of the findings, data analysis and writing the final manuscript. T. N. C. contributed to data analysis, interpretation of the findings and writing the final manuscript. S. K. J. contributed to formulating the research questions, study design, laboratory analyses, data analysis, interpretation of the findings and writing the final manuscript.

The authors declare that there are no conflicts of interest.

\section{References}

1. Kono N \& Arai H (2015) Intracellular transport of fat-soluble vitamins A and E. Traffic 16, 19-34.

2. Jensen SK, Engberg RM \& Hedemann MS (1999) All-rac$\alpha$-tocopherol acetate is a better vitamin E source than all-rac$\alpha$-tocopherol succinate for broilers. J Nutr 129, 1355-1360. 
3. Hymøller L, Clausen TN \& Jensen SK (2016) Interactions between retinol, $\alpha$-tocopherol and cholecalciferol need consideration in diets for farmed mink (Mustela vison). Br J Nutr 115, 751-758.

4. Hedemann M \& Jensen S (1999) Vitamin E status in newly weaned piglets is correlated to the activity of carboxylester hydrolase in pancreatic tissue. In Manipulating Pig Production VII Proceedings of the Seventh Biennial Conference of the Australasian Pig Science Association, p. 181 [PD Cranwell, editor]. Werribee: APSA.

5. Hedemann MS, Clausen T \& Jensen SK (2011) Changes in digestive enzyme activity, intestine morphology, mucin characteristics and tocopherol status in mink kits (Mustela neovision) during the weaning period. Animal 5, 394-402.

6. Burton GW, Traber MG, Acuff RV, et al. (1998) Human plasma and tissue alpha-tocopherol concentrations in response to supplementation with deuterated natural and synthetic vitamin E. Am J Clin Nutr 67, 669-684.

7. Jensen SK, Nørgaard JV \& Lauridsen C (2006) Bioavailability of $\alpha$-tocopherol stereoisomers in rats depends on dietary doses of all-rac-or RRR- $\alpha$-tocopheryl acetate. Br J Nutr 95, 477-487.

8. Blatt DH, Pryor WA, Mata JE, et al. (2004) Re-evaluation of the relative potency of synthetic and natural $\alpha$-tocopherol: experimental and clinical observations. J Nutr Biochem 15, 380-395.

9. Council NR \& Council NR (2000) Dietary Reference Intakes for Vitamin C, Vitamin E, Selenium, and Carotenoids. Washington, DC: National Academies Press.
10. Kuchan MJ, Jensen SK, Johnson EJ, et al. (2016) The naturally occurring $\alpha$-tocopherol stereoisomer $R R R$ - $\alpha$-tocopherol is predominant in the human infant brain. Br J Nutr 116, 126131.

11. Gaur S, Kuchan MJ, Lai C-S, et al. (2017) Supplementation with $R R R$-or all-rac- $\alpha$-tocopherol differentially affects the $\alpha$ tocopherol stereoisomer profile in the milk and plasma of lactating women. J Nutr 147, 1301-1307.

12. Kaneko K, Kiyose C, Ueda T, et al. (2000) Studies of the metabolism of $\alpha$-tocopherol stereoisomers in rats using [5-methyl-14C] SRR-and RRR- $\alpha$-tocopherol. J Lipid Res $\mathbf{4 1}$, 357-367.

13. Ingold K, Burton G, Foster D, et al. (1987) Biokinetics of and discrimination between dietary $R R R$ - and $S R R-\alpha$-tocopherols in the male rat. Lipids 22, 163-172.

14. Hosomi A, Arita M, Sato Y, et al. (1997) Affinity for $\alpha$-tocopherol transfer protein as a determinant of the biological activities of vitamin E analogs. FEBS Lett 409, 105-108.

15. Traber MG, Elsner A \& Brigelius-Flohé R (1998) Synthetic as compared with natural vitamin $\mathrm{E}$ is preferentially excreted as $\alpha$-CEHC in human urine: studies using deuterated $\alpha$-tocopheryl acetates. FEBS Lett 437, 145-148.

16. Weiser H \& Vecchi M (1982) Stereoisomers of alphatocopheryl acetate. II. Biopotencies of all eight stereoisomers, individually or in mixtures, as determined by rat resorption-gestation tests. Int J Vitam Nutr Res 52, $351-370$. 